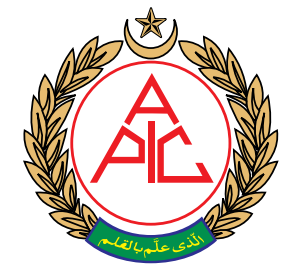

Orthotedic surgeon,

Baghdad, Iraq

Correspondence:

Amjed Hammodi,

Orthotedic surgeon,

Baghdad, Iraq

Phone: + 9647817749052

E-mail: amjidhammodi@yahoo.

com

Received: 11 June 2019,

Reviewed \& Accepted: 12

June 2019

\section{Anatomical gates for pain relief due to cervical and lumbar disc disease}

\author{
Amjed Hammodi
}

\begin{abstract}
I propose the theory that the nerve sheath is transmitting the lignocaine chemical upwards towards the dorsal root ganglia and nerve roots which produce pain due to excitation after the disc disease. In this way, an injection of local anesthetic given far away from the actual neural damage, at a peripheral site, can relieve the pain for a variable length of time. In this case report, the author describes four specific injection points, called 'Gates'; two of these describe pain relief in neck and upper limb, while two are specific to low back pain, hip pain and lower limb pains. Each of these was successfully used in a patient with specific pain of variable duration.
\end{abstract}

Certainly, controlled studies with larger sample size, are needed to be done to understand better that how these distal nerve blocks really work.

Key words: Nerve sheath; Dorsal root ganglia; Pain; Pain relief; Voltage gated blockers; Lignocine

Citation: Hammodi A. Anatomical gates for pain relief due to cervical and lumbar disc disease. Anaesth. pain \& intensive care 2019;23(2):217-220

\section{INTRODUCTION}

Cervical and lumbar spine disc disease might cause severe pain unable to be controlled by oral medications. Epidural steroid injections (ESI) are usually done in theatre under fluoroscopic or ultrasound guidance. The success rates of the cervical and lumbar ESIs are $63 \%$ and $81 \%$ respectively. ${ }^{1,2}$

Cervical and lumbar ESIs have been linked to serious complications and are not FDA approved., 3 In this case series I describe for the first time four new injections with lignocaine, e.g. two injection points (Gate A and Gate B) in the upper limb and two points (Gate C and Gate D) in the lower limb, which relieve cervical and lumbar spine disc disease pain respectively, with pain relief which may last for up to one year in some cases.

I propose the theory that the injected lignocaine chemical is transmitted through the nerve sheath upwards towards dorsal root ganglia and nerve roots which are excited by the disc disease.
I describe in this case series four injection gates for sodium channel blockers (Figure 1).

These injection gates require no corticosteroids, no $\mathrm{x}$-ray, no nerve stimulating device, no ultrasound guidance and no theatre set up.

Four gates have been discovered (Figure 1). Gate $A$ and Gate B are for upper limb radiculopathy and neck pain related to cervical spine disc disease and any nerve pain in the upper limbs. These two gates will relieve pain in the neck, upper chest, upper back and also any nerve pain in the upper limbs regardless of the cause whether it is related to cervical spine disc disease or distal to it.

Gate C and Gate D, are for sciatica and lower back pain related to lumbar disc disease and also any nerve pain in the lower limbs.

Gates A and D injections will cause pain relief within five minutes, whilst Gates B and C injections will cause pain relief in thirty minutes after the injections I defined the 'anatomical gate' as a space in which 


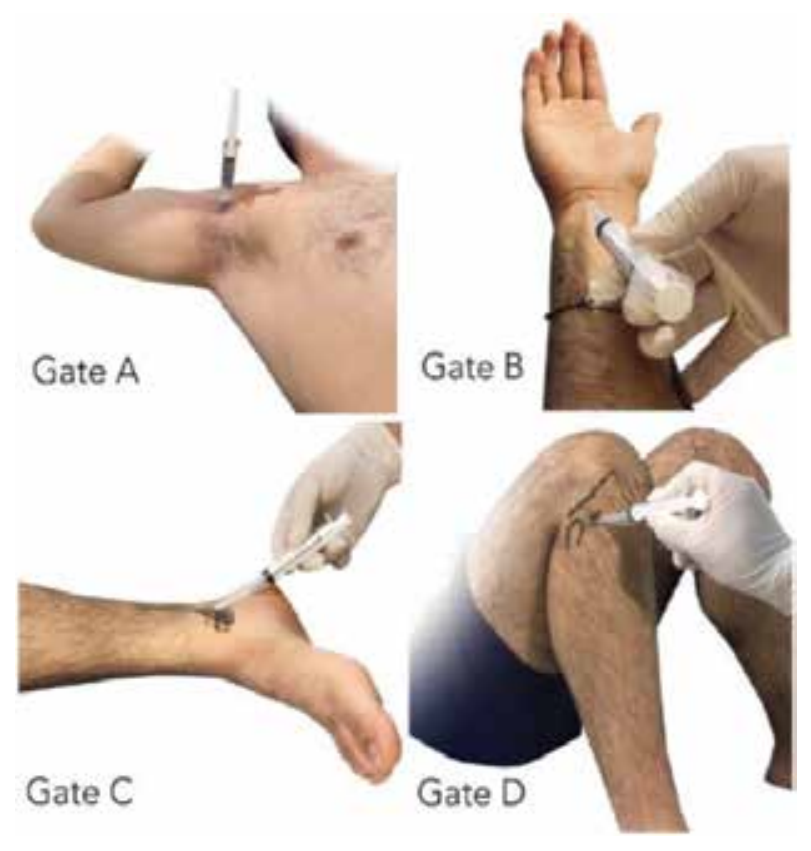

Figure 1: The antomical gates of sodium channel blockers

lignocaine injection can be done without ultrasound, $\mathrm{x}$-ray or nerve stimulator guidance and can be verified successful by numbness in specific dermatomes (thumb, index, middle and half ring fingers in case of Gate B injection, carpal tunnel injection, and heel numbness in Gate $\mathrm{C}$ injection, tarsal tunnel injection, or subjective substantial relief of pain within five minutes as in Gate A and Gate D injections, with pain relief lasting from one week to one year. Gates A and $\mathrm{D}$ injections will cause no motor or sensory deficits in the upper and lower limbs respectively.

\section{CASE REPORT 1}

A middle aged lady, 48, with no co-morbidities, had severe chronic neck pain, right sided radiculopathic pain of VAS score 9, and occasional episodes of severe vertigo, for the last 15 years.

She had normal neurological examination of both her upper limbs. MRI showed C5/C6 prolapsed disc.

Patient had had Gate A injection in her right axilla. $3 \mathrm{~mL}$ of $2 \%$ lignocaine was added to $7 \mathrm{~mL}$ of distilled water in a $10 \mathrm{~mL}$ syringe. Patient was in supine position with head turned to other side, and 90 degrees abduction and full external rotation of shoulder with 90 degrees elbow flexion. The axillary artery was palpated and the needle advanced above the artery into the bicipital groove of the humerus. After touching the groove, the needle was retracted only enough to inject the lignocaine.
The patient has been pain free after the injection for eleven months now.

\section{CASE REPORT 2}

A 62 years old man with hypertension only, described severe right upper limb radiculopathic pain, VAS score was 9 for the last 4 weeks for which oral medications did not help. He had normal neurological examination in his upper limbs and MRI confirmed prolapse of $\mathrm{C} 5 / \mathrm{C} 6$ disc.

He was given Gate B injection, in the carpal tunnel injection with lignocaine only. The patient described $75 \%$ pain relief $30 \mathrm{~min}$ after the injection and complete relief of pain one week after the injection for the last eight months.

\section{CASE REPORT 3}

An old lady, 66 y, with known chronic lower back pain and left sciatica, VAS score 7 for more than ten years. She had normal neurologic tests and SLR. MRI showed L4/L5 prolapsed disc.

She was given Gate $\mathrm{C}$ injection one year back. The injection was made in the tarsal tunnel. $10 \mathrm{~mL}$ syringe, $23 \mathrm{G}$ needle $(7 \mathrm{~mL}$ total volume - $3 \mathrm{~mL} 2 \%$ lignocaine plus $4 \mathrm{~mL}$ distilled water). It takes around $30 \mathrm{~min}$ for pain relief to be sensed.

Patient positioned supine with external rotation of hip in the same side of injection. The needle was introduced through a point just distal and posterior to medial malleolus. The needle was in 45 degrees inclination to horizontal plane with the needle tip towards the patient head and facing posteriorly progressing from distal to proximal with needle going parallel to tibia shaft. The injection volume was deposited at different depths as the needle was progressed deeper with aspiration before each injection in order not to miss the tarsal tunnel.

The patient felt paresthesia in her heel in $10 \mathrm{~min}$ after the injection was made into the tarsal tunnel. and has been complete pain free till now.

\section{CASE REPORT 4}

A young man of 24 years of age presented with severe right sided sciatica for six months.

Patient had normal neurology in both lower limbs and his SLR was 60 degrees. MRI showed L5/S1 prolapsed disc. He had an ESI that failed to relieve his pain.

This patient was given Gate $\mathrm{D}$ injection and is pain free for the last two months following the injection. 
Gate $\mathrm{D}$ is an injection in the upper tibiofibular joint with $10 \mathrm{~mL}$ syringe $(3 \mathrm{~mL}$ of $2 \%$ lignocaine plus 7 $\mathrm{mL}$ of distilled water).

Gates A and D injections caused no motor or sensory deficits in the upper and lower limbs respectively.

\section{DISCUSSION}

How come a peripheral injection can relieve pain when the cause of pain lies more proximally? How can the effect of a simple lignocaine injection last for months when the half-life of lignocaine is only about one hour? To understand it we have to understand the following:

After nerve injury hyperexcitability and spontaneous firing develop at the site of injury and also in the dorsal root ganglion cell bodies. This hyperexcitability results at least partly from accumulation of sodium channels at the site of injury. ${ }^{5}$ Pain is related to excited nerves and disturbance in voltage-gated sodium channels. The relationship between voltagegated sodium channels and pain has been reported in many published studies. ${ }^{6-11}$

Simply by giving lignocaine, which is a sodium channel blocker, you are resetting the electrogenicity of nerves like resetting a jammed laptop.

The local anesthetic molecule consists of three components: (a) lipophilic aromatic ring, (b) intermediate ester or amide chain, and (c) a terminal amine. ${ }^{1}$ The aromatic ring improves lipid solubility. ${ }^{1-3}$ The nerve membrane consists of a double lipid layer and a protein layer and therefore, the property of enhancing lipid solubility contributes to increased potency of the anesthetic agent as more of the available drug can diffuse through the membrane. ${ }^{12}$ Myelin sheath is characterized by a high proportion of lipid (70 to $85 \%)$. $^{13}$

Lignocaine will diffuse through the myelin sheath covering the nerve and in case of blocking a peripheral nerve the diffusion will carry on throughout the whole nerve blocking the sodium channels, which are accumulated at the site of injury.

The hypothesis is diffusion will occur through the uninterrupted myelin sheath covering the main nerve and its branches and by injecting one division of the main nerve the lipid based chemical will diffuse to the main nerve and its other branches.
The author hopes that these new injections are scrutinized further in big studies to prove their efficacy. The author theorizes that the diffusion of a particular chemical through the myelin sheath of nerves and its efficacy in treating pain depends on the following criteria:

1) The Lipid solubility of the injected chemical. The more the solubility the more diffusion through the myelin sheath (which is mainly made off lipid), the more solubility the better.

2) The volume of the injected chemical. The more volume the more is the effect.

3) Distance from the Dorsal Root Ganglia. The shorter the distance the better the effect.

4) Characteristics of the myelin sheath of different nerves, as the different nerves differ in the content of myelin.

5) The distance of the injection to the nerve. The shorter, the better is the effect.

Of course the above-mentioned points need extensive research studies to prove or refute them and the author suggests the use of contrast material, as it is used in myelography, to prove that the chemicals can diffuse and travel proximally in the peripheral nerves. Contrast material, for example, can be injected in the tarsal tunnel and followed up by radiology done at various times to study this phenomenon. With this approach, we could gain a lot of knowledge in regards to nerve function and the scope of that knowledge would be limitless.

\section{CONCLUSION}

With the discovery of the voltage-gated sodium channel blocker gates, it has become easy to diagnose and treat many conditions in the musculoskeletal systems, which have been treated with difficulty and poor results.

These gates injections are an easy, safe and effective method of pain management related to nerves in the upper and lower limbs.

Conflict of interest: None declared by the author 


\section{the anatomical gates}

\section{REFERENCES}

1- Baral BK, Shrestha RR, Shrestha AB, Shrestha CK. Effectiveness of epidural steroid injection for the management of symptomatic herniated lumbar disc. Nepal Med Coll J. 2011 Dec;13(4):303-7. [PubMed]

2- Lin E, Lieu V, Halevi L, Shamie A, Wang J. Cervical epidural steroid injections for symptomatic disc herniations. J Spinal Disord Tech. 2006 May;19(3):183-6. [PubMed] DOI: 10.1097/01.bsd.0000190558.13248. e1

3- Epstein NE. Major risks and complications of cervical epidural steroid injections: an updated review. Surg Neurol Int. 2018 Apr 23:9:86. [PubMed] DOI: 10.4103/sni. sni 8518

4- Epstein NE. The risks of epidural and transforaminal steroid injections in the Spine: Commentary and a comprehensive review of the literature. Surg Neurol Int. 2013 Mar 22;4(Suppl 2):S74-93. [PubMed] DOI:
10.4103/2152-7806.109446

5- Kalso E. Sodium channel blockers in neuropathic pain. Curr Pharm Des. 2005;11(23):3005-11. [PubMed]

6- Dib-Hajj SD, Black JA, Waxman SG. Voltage-gated sodium channels: therapeutic targets for pain. Pain Med. 2009 0ct;10(7):1260-9. [PubMed] DOI: 10.1111/j.15264637.2009.00719.x

7- Bennett DL, Clark AJ, Huang J, Waxman SG, Dib-Hajj SD. The Role of Voltage-Gated Sodium Channels in Pain Signaling. Physiol Rev. 2019 Apr 1;99(2):1079-1151. [PubMed] DOI: 10.1152/physrev.00052.2017

8- Levinson SR1, Luo S, Henry MA. The role of sodium channels in chronic pain. Muscle Nerve. 2012 Aug;46(2):155-65. [PubMed] DOl: 10.1002/mus.23314

9- Wood JN, Boorman JP, Okuse K, Baker MD. Voltage-gated sodium channels and pain pathways. J Neurobiol. 2004 0ct;61(1):55-71. [PubMed] DOI: 10.1002/neu.20094

10- Cummins TR, Sheets PL, Waxman $S G$. The roles of sodium channels in nociception: implications for mechanisms of pain. Pain. 2007 Oct;131(3):243-57. [PubMed] DOl: 10.1016/j.pain.2007.07.026

11- Kanellopoulos AH, Matsuyama A. Voltage-gated sodium channels and pain-related disorders. Clin Sci (Lond). 2016 Dec 1;130(24):2257-65. [PubMed] DOI: 10.1042/CS20160041

12- Moodley DS. Local anaesthetics in dentistry - Part 2: Choice of local anaesthetic agent. S Afr Dent J. 2017; 72(3):128-30. [Free full text]

13- Morell P, Quarles RH. Characteristic Composition of Myelin. In: Siegel GJ, Agranoff BW, Albers RW, et al., editors. Basic Neurochemistry: Molecular, Cellular and Medical Aspects. 6th edition. Philadelphia: Lippincott-Raven; 1999. Available from: https://www.ncbi.nlm.nih.gov/ books/NBK28221/ 